\title{
ALTERAÇÕES DE PAISAGENS RIBEIRINHAS: O CASO DO RIO PARAMOPAMA, ESTADO DE SERGIPE
}

\author{
Luísa Ferreira Ribeiro ${ }^{1}$, Francisco Sandro Rodrigues Holanda ${ }^{2}$, Renisson Neponuceno de Araújo Filho ${ }^{3}$, \\ Igor Pinheiro Rocha ${ }^{4}$, Suzilane Santos Gois ${ }^{5}$ \\ ${ }^{1}$ Bióloga, M.Sc., UFS, São Cristóvão, SE, Brasil - luisaferreira@oi.com.br \\ ${ }^{2}$ Eng. Agrônomo, Dr., Depto. de Engenharia Agronômica, UFS, São Cristóvão, SE, Brasil - fholanda@infonet.com.br \\ ${ }^{3}$ Eng. Florestal, UFS, São Cristóvão, SE, Brasil - nepoaraujo@ hotmail.com \\ ${ }^{4}$ Eng. Florestal, M.Sc., UFS, São Cristóvão, SE, Brasil - rochaigor@ hotmail.com \\ ${ }^{5}$ Eng. Florestal, UFS, São Cristóvão, SE, Brasil - suzilane_gois@ hotmail.com \\ Recebido para publicação: 15/07/2009 - Aceito para publicação: 28/08/2010
}

\begin{abstract}
Resumo
Os objetivos deste trabalho foram analisar as alterações da paisagem promovidas pela erosão marginal e verificar a eficácia da técnica de bioengenharia de solos na recuperação das margens de um trecho do rio Paramopama, localizado no município de São Cristóvão, estado de Sergipe. Para a avaliação da alteração da paisagem, classificada como de altíssimo, alto e baixo grau de antropização, foram analisadas séries fotográficas compreendidas no período de 1998-2008. As espécies que se estabeleceram com maior ocorrência foram as pertencentes à família Poaceae. Dentre os fatores responsáveis pela alteração da paisagem, destacaram-se a erosão e a instalação de dutos atravessando a calha do rio. No rio Paramopama, foram observados dois momentos distintos, um com altíssimo e outro com alto grau de antropização. A técnica de bioengenharia de solos mostrou-se eficiente no que se refere à recuperação da paisagem, além de prover condições para a recuperação do ecossistema ribeirinho.

Palavras-chave: Margens de cursos d’água; recuperação de paisagem; antropização.
\end{abstract}

\begin{abstract}
Riverine landscape changes: case-study of Paramopama River, Sergipe State. This work aimed to analyze current changes caused by riverbank's erosion, as well as to verify the effectiveness of soil bioengineering techniques on the landscape recovery applied to Paramopama River banks. In order to verify landscape's changes, it analyzed a photographic set produced during the period of 1998-2008, which had been classified according to its degree of anthropization as very high, high and low degree. Species with higher occurrence were those belonging to botanic family of Gramineae. There were many factors to landscape change, erosion was the most important followed by disturbances caused by ducts installation across the river channel. At Paramopama River two different moments could be observed, firstly, a very high degree of anthropization followed by a high degree of anthropization. Soil bioengineering technique was efficient to landscape recovery, providing ecological conditions to ecosystem recovery.

Keywords: Stream banks; landscape recovery; anthropization.
\end{abstract}

\section{INTRODUÇÃO}

As margens dos cursos d'água vêm sendo cada vez mais exploradas, tanto para fins comerciais quanto para atender às necessidades dos ribeirinhos. A retirada da vegetação, entre outras, é a mais destacada forma de degradação nesse ecossistema.

Uma das consequências da exploração das zonas ripárias é a formação de fragmentos, cujo maior impacto é a perda da biodiversidade regional, sendo que quanto mais fragmentadas e perturbadas forem essas paisagens, maiores são os desafios para a sua conservação (VIANA, 1995), impondo a necessidade de se considerar um padrão temporal de variação da zona ripária (GREGORY et al., 1992).

Além das perdas referentes à devastação da vegetação natural, gerando desconforto térmico e desarmonia paisagística, observa-se que em áreas fragmentadas ocorre a interferência na dinâmica das 
microbacias hidrográficas, tendo como principal consequência o desenvolvimento da erosão hídrica (CARRIJO; BACCARO, 2000).

A degradação das margens dos rios e a erosão resultante ocasionam alterações da paisagem local. Para Bertrand (1972), a paisagem não é a simples adição de elementos geográficos, mas uma determinada porção do espaço, resultado da combinação dinâmica, portanto instável, de elementos físicos, biológicos e antrópicos que, agindo dialeticamente uns sobre os outros, originam um conjunto único e indissociável, em perpétua evolução.

Ainda sobre o conceito de paisagem, Lucas (1991) cita que o termo "paisagem" leva em conta os componentes naturais, como a geomorfologia e a vegetação, os fatores de intervenção humana, como o manejo da vegetação, e as qualidades estéticas, que estão relacionados à reação mental do que os olhos veem.

A paisagem pode ser classificada, segundo Lima et al. (2004), quanto à sua qualidade, que tem como base o impacto decorrente da interferência antrópica, sendo sugeridas as seguintes classes: altíssimo, alto, médio e baixo grau de antropização. De acordo com os autores, um altíssimo grau de antropização refere-se à inexistência da vegetação, ou seja, um solo exposto contribui para o desencadeamento dos processos erosivos. $\mathrm{O}$ alto grau de antropização é representado pelos elementos construídos pelo homem, artificializando a paisagem através de edificações. O médio grau de antropização indica que a alteração na paisagem ocorreu, entretanto não trouxe maiores problemas para sua qualidade, como plantios de espécies arbóreas para indústria. $\mathrm{O}$ baixo grau de antropização refere-se às áreas que apresentam as condições naturais ou seminaturais, onde se observa que a ação antropogênica é inexistente ou pouco representativa.

A recuperação de áreas degradadas é essencial para que o ecossistema volte a desempenhar suas funções, uma vez que o processo de eliminação das florestas resulta num conjunto de problemas ambientais, como a extinção de várias espécies da fauna e da flora, mudanças climáticas locais, erosão dos solos e eutrofização e assoreamento dos cursos d'água (FERREIRA; DIAS, 2004).

Ambientes florestais alterados por distúrbios de origem natural ou antrópica podem receber, através da fauna, uma importante contribuição para a recolonização e reestruturação de sua vegetação (MARTÍNEZ-RAMOS; SOTO-CASTRO, 1993; WHITTAKER; JONES, 1994; PARROTA et al., 1997; WUNDERLE, 1997). Animais como aves e mamíferos podem transportar uma grande quantidade de sementes de diversas espécies para esses locais, catalisando os processos de regeneração vegetal (HOWE; SMALLOWOOD, 1982).

Entre as diversas técnicas para recuperação de áreas ribeirinhas, a bioengenharia de solos tem se apresentado como uma alternativa ambientalmente sustentável, a partir do uso de estruturas biodegradáveis, como fibras vegetais, estacas vivas, madeira e estruturas rígidas, como pedra, concreto e ferro, entre outros (SCHIELTZ; STERN, 1996; GOMES, 2005). Segundo Gray; Sotir (1996), trata-se de uma técnica que associa baixo custo, por utilizar material natural, muitas vezes advindos da própria região, à eficiência na estabilização dos taludes marginais e na melhoria visual da área recuperada, uma vez que aumenta a área verde, reduzindo o impacto visual. Tais vantagens muitas vezes não são encontradas em outras técnicas utilizadas para a recuperação de cursos d'água.

Este trabalho teve como objetivo analisar as alterações da paisagem promovidas pela erosão marginal e verificar a eficácia da técnica de bioengenharia de solos na recuperação das margens de um trecho do rio Paramopama, localizado no município de São Cristóvão, estado de Sergipe.

\section{MATERIAL E MÉTODOS}

\section{Caracterização da área de estudo}

A área estudada está situada na faixa de dutos Atalaia-Itaporanga, no município de São Cristóvão, e devido à implantação desses dutos tem havido intervenções repetidas no leito do rio Paramopama, levando à ocorrência de processos erosivos, que alteram fortemente a paisagem local.

O rio Paramopama nasce no município de São Cristóvão, estado de Sergipe, corre em vales normais encaixados no relevo colinoso dos sedimentos do Grupo Barreiras e despeja suas águas em um braço de maré na margem esquerda do estuário do rio Vaza-Barris (Figura 1). Prevalecem, em todo o município, solos profundos e bem drenados (Argissolos Vermelhos-Amarelos), seguidos por solos Neossolos Flúvicos e Gleissolos nas margens e nas várzeas dos rios e mangues (EMPRESA BRASILEIRA DE PESQUISA AGROPECUÁRIA (EMBRAPA, 1999). A área estudada é dominada por solos classificados como Neossolo Flúvico nas margens do rio e Argissolo Vermelho-Amarelo nas partes mais altas do relevo. 


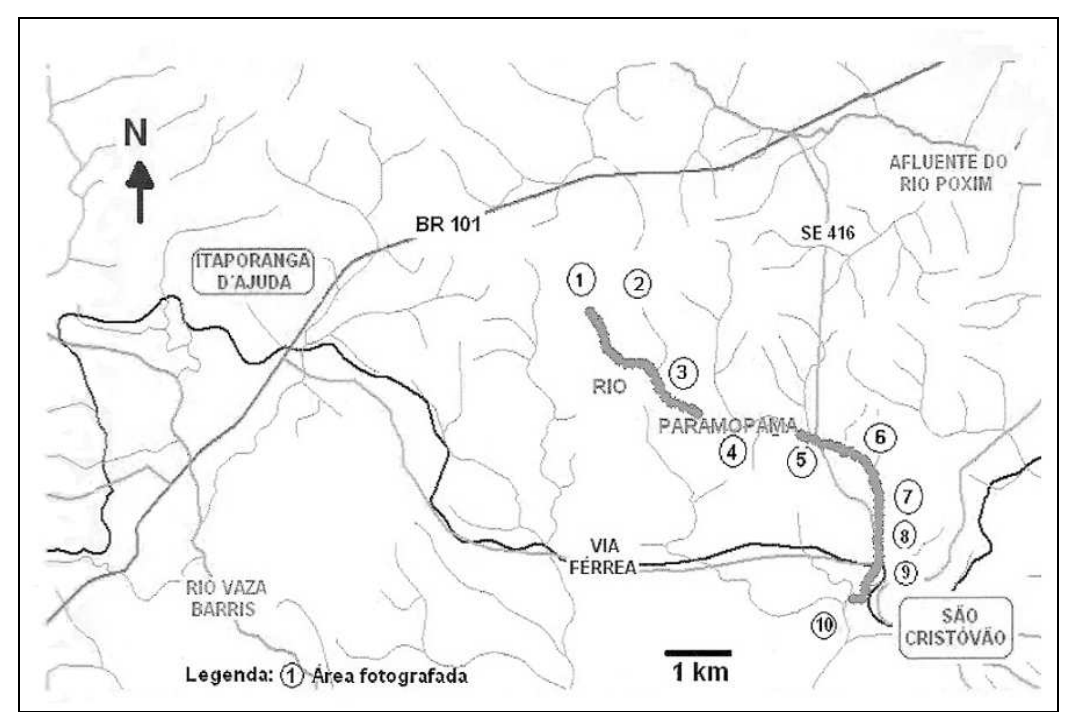

Figura 1. Localização do rio Paramopama, São Cristóvão, SE (SANTOS, 2007).

Figure 1. Localization of Paramopama River, São Cristóvão, SE (SANTOS, 2007).

\section{Implantação de biotécnicas e coleta de dados}

O monitoramento do processo erosivo foi realizado no período de janeiro de 2005 , quando da implantação de novos dutos, a maio de 2008. Em setembro de 2006 foi verificado na área forte processo erosivo, quando então foram implantadas as técnicas de bioengenharia de solos.

A técnica de bioengenharia de solos empregada é constituída pela associação de Gabião do tipo Colchão Reno® (MACCAFERRI DO BRASIL LTDA), com espécies vegetais e dois tipos de geotêxtil: Tela Syntemax ${ }^{\circledR}$ 400TF (composta por fibras de palha, fibras mistas - palha e fibra de coco -, entrelaçadas por meio de uma costura industrial longitudinal, com redes resistentes de polipropileno fotodegradável) e Tela Fibrax ${ }^{\circledR}$ 400BF (constituída 100\% por fibras de coco, entrelaçadas por costura longitudinal, com fios de polipropileno fotodegradável) (DEFESA FLORESTAL LTDA (DEFLOR), 2005). O Colchão Reno® é definido como estrutura retangular em forma de grade, caracterizada por possuir comprimento e largura muito maior que a altura normal. Quando instalados, são preenchidos com pedras de granulometria média, tornando-se elementos drenantes (MACCAFERI, 2008). O referido colchão foi instalado na zona de variação da cota rio, bem como na sua calha. O geotêxtil Syntemax ${ }^{\circledR}$ 400TF foi instalado nas áreas externas e nas áreas mais próximas do curso d'água, enquanto o geotêxtil Fibrax® 400BF foi instalado entre o geotêxtil Syntemax ${ }^{\circledR}$ 400TF (Figura 2).

Compondo as biotécnicas implantadas, e como contribuição para a fixação dos geotêxteis, foram semeadas a lanço sementes das espécies vegetais braquiária (Brachiaria decumbens Stapf.), calopogônio (Calopogonium muconoides Desv.), crotalária (Crotalaria spectabilis Roth.) e feijão-guandu (Cajanus cajan (L.) Millsp), e plantadas mudas de capim vetiver (Vetiveria zizanoides (L.) Nash), em espaçamento $0,50 \times 0,50 \mathrm{~m}$

Para a avaliação das alterações da paisagem do rio Paramopama, foram utilizadas fotografias para a comparação dos períodos anterior e posterior à implantação das técnicas de bioengenharia, durante o período de setembro de 2006 a maio de 2008. Na coleta de dados no campo, com auxílio também da análise das fotografias, foi possível identificar os fatores responsáveis por tais alterações.

Para interpretação visual das fotografias, foi executada a metodologia de análise da qualidade visual da paisagem, proposta por Landovsky et al. (2006), empregando uma escala compreendendo valores inteiros iguais a 1, 2, 3, 4 e 5, correspondendo às classes de qualidade visual baixa, média baixa, média, média alta e alta, respectivamente (Tabela 1).

Após a avaliação da Qualidade Visual, utilizou-se a metodologia proposta por Lima et al. (2004) para avaliação da qualidade da paisagem quanto ao grau de antropização. Nessa avaliação, foi empregada uma escala compreendendo valores inteiros iguais a 1,2, 3 e 4, correspondendo às classes de altíssimo, alto, médio e baixo grau de antropização, respectivamente (Tabela 2). 
Tela Syntemax $\circledR_{400 B F}$

Tela Fibrax ${ }^{\circledR}$ 400BF

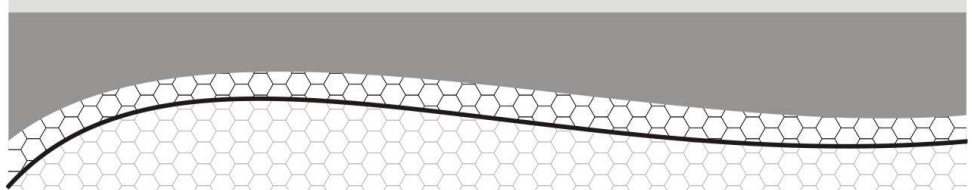

Colchão Reno®®

Rio Paramopama

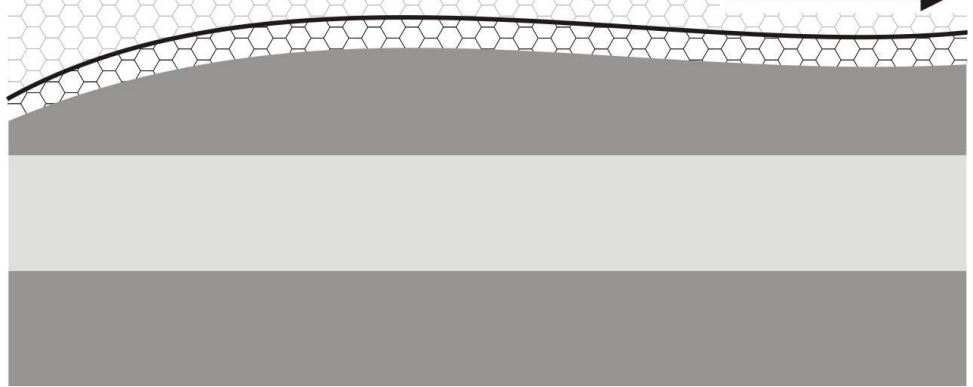

Figura 2. Disposição dos elementos de bioengenharia no sítio experimental.

Figure 2. Bioengineering technique display in the experimental plots.

Tabela 1. Valor individual de cada elemento adotado na valoração da paisagem.

Table 1. Individual values of each adopted element in the landscape valuation.

\begin{tabular}{lcc}
\hline Classe & Elemento & Valor individual \\
\hline 1 & Água & 5 \\
2 & Mata & 5 \\
3 & Reflorestamento & 2 \\
4 & Agricultura & 3 \\
5 & Área urbana/Rodovia & 3 \\
6 & Campo/Pastagem & 4 \\
7 & Solo exposto & 1 \\
8 & Solo com calcário & 1 \\
9 & Afloramento rochoso & 5 \\
\hline
\end{tabular}

Tabela 2. Classes de grau de antropização da paisagem.

Table 2. Classes of anthropization of the landscape.

\begin{tabular}{lcc}
\hline Classe & Elemento & Valor individual \\
\hline Altíssimo grau de antropização & Inexistência de vegetação & 1 \\
Alto grau de antropização & Áreas de agricultura e pastagem; vegetação & 2 \\
Médio grau de antropização & secundária & 3 \\
Baixo grau de antropização & Manejo florestal & 4 \\
\hline
\end{tabular}

\section{RESULTADOS E DISCUSSÃO}

\section{A erosão na margem do rio Paramopama}

A área estudada sofreu uma forte alteração da paisagem, ocasionada por perturbações na margem e calha do rio, que se originaram nas primeiras intervenções registradas a partir da colocação dos 
primeiros dutos, ainda na década de 1990. O intenso e continuado processo erosivo e os movimentos de massa ocorridos no talude do rio causaram o efeito da retirada da vegetação ripária e não permitiram que as espécies arbustivas e arbóreas, a partir de dispersão de sementes proveniente do remanescente de mata atlântica da área vizinha, se desenvolvessem plenamente, agravando e facilitando a erosão nas margens do rio. Na margem do rio Paramopama, o tipo de movimento de massa predominante é o escorregamento rotacional, que são movimentos rápidos de massa de solo, de curta duração, em volume bem definido no terreno, cujo centro de gravidade se desloca para baixo e para fora do talude, conforme descrito por Maciel Filho (1997).

A forma atual do canal reflete o ajustamento do rio aos débitos, considerando que é resultante da ação exercida pelo fluxo sobre os materiais componentes do leito e das margens. É possível observar que a magnitude dos débitos na calha do rio Paramopama está relacionada a aspectos como a distribuição e frequência dos fluxos e alterações, que têm levado a fortes mudanças na morfologia das suas margens, com consequente aceleração da erosão do seu talude e assoreamento do seu canal.

A degradação nas margens em decorrência da implantação de dutos teve como consequência direta o processo erosivo e a transformação da paisagem local. O sistema radicular das espécies ocorrentes na área, na sua maioria gramíneas ou ciperáceas, não promoveu resistência suficiente ao talude que viesse impedir a ação do processo erosivo, levando ao seu arraste, a partir do desmoronamento de blocos do talude da margem do rio, além de não permitirem a diversidade tanto da flora quanto da fauna.

Observou-se, na paisagem local, dominância das espécies Brachiaria decumbens Stapf., pertencente à família Poaceae, e Cyperus flavus J. Presl e C. Presl, pertencente à família Cyperaceae, espécies que apresentam comportamento agressivo, rusticidade e grande competitividade, além de fácil adaptação em ambientes degradados.

\section{Qualidade da paisagem}

A qualidade da paisagem avaliada durante o período de 2006 a 2008 foi influenciada pela presença do processo erosivo em todo o trecho estudado, com pontos onde a erosão se mostrou bastante acelerada, contrastando com outros pontos onde a erosão se apresentou com menor intensidade. Os elementos observados na margem do rio Paramopama para valoração da paisagem foram água, mata e solo exposto. A mata visualizada na área do entorno encontra-se conservada, apresentando, entretanto, espécies arbustivas, na sua maioria de grande porte, e solo exposto, consequência do processo erosivo. Desse modo, observando os valores propostos por Landovsky et al. (2006), no quadro 1, a qualidade da paisagem variou entre 1 e 5 , sendo " 1 " referente ao solo exposto e "5" referente ao elemento água. Mesmo apresentando solo exposto, a presença dos elementos "água" e "mata" da paisagem nas áreas de entorno, embora seja perceptível um mosaico com áreas já ocupadas com pastagens, vem potencializar uma possível recuperação da paisagem.

De acordo com Lima et al. (2004), no quadro 2, o grau de antropização observado na área antes das intervenções para a sua recuperação foi classificado como "altíssimo", uma vez que foi observada a inexistência de cobertura vegetal, em consequência das primeiras e profundas intervenções ocorridas na calha e na margem do rio, para a colocação dos dutos. No trecho avaliado, caracteriza-se uma paisagem de baixa qualidade. $\mathrm{O}$ solo exposto, sujeito a repetidos movimentos de massa em cada período chuvoso, de alta vazão na calha do rio, retroalimentava os processos erosivos marginais e o consequente alargamento do canal e posterior assoreamento.

\section{Recuperação da margem do rio Paramopama}

Diante do altíssimo grau de antropização, foram implantadas biotécnicas para a recuperação da margem. Essas técnicas têm sido utilizadas com frequência quando o objetivo é, além de recuperar a área degradada, também recuperar a paisagem que foi alterada em decorrência do processo erosivo (HOLANDA et al., 2008).

A reconstituição das matas ciliares é fundamental para a qualidade e o volume das águas e para o equilíbrio dos ecossistemas aquáticos, uma vez que essa vegetação funciona como filtro ambiental, retendo poluentes e sedimentos que chegariam aos cursos d'água (DAVIDE et al., 2002). Para se estabelecer ambiente favorável para a recuperação da mata ciliar, foi então trabalhada a técnica de bioengenharia de solos, para controle do processo erosivo, a partir da estabilização do talude. 

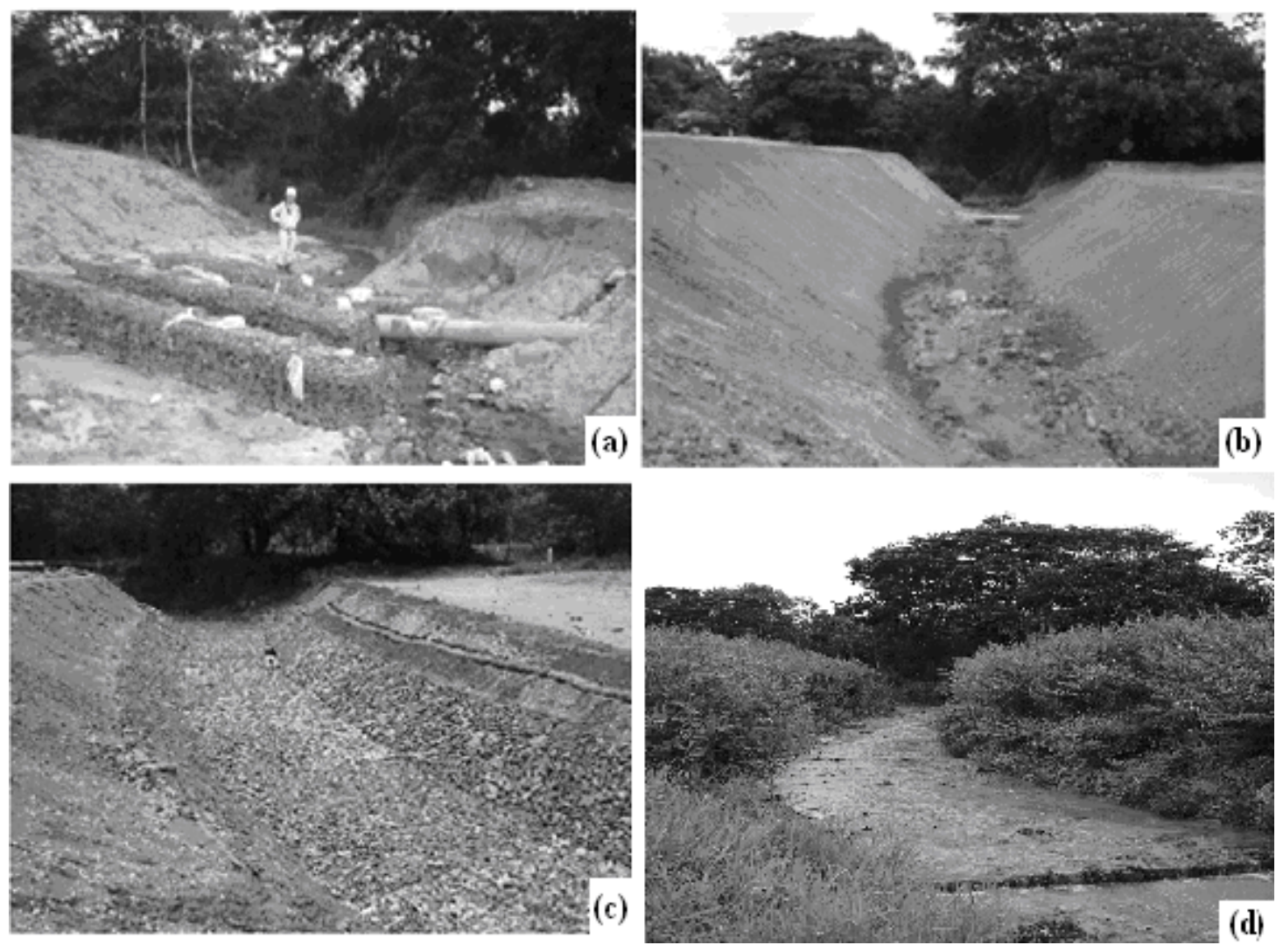

Figura 3. Implantação das biotécnicas. (a) Margem e canal degradado, com exposição de duto; (b) Retaludamento da margem para implantação das biotécnicas; (c) Instalação do Colchão Reno®, remodelamento do canal do rio; (d) Calha do rio recoberta pelo Colchão Reno®, com implantação do geotêxtil (setembro/2006).

Figure 3. Implementation of biotechniques. (a) Degraded channel and river-margin, with ducts exposition; (b)Regrading the margin in order to install the biotechniques (c) Installation of gabion mattress remodeling the river channel; (d) River bed covered by gabion mattress with the implementation of geotextile (September/2006).

Uma vez verificada a aceleração do processo erosivo, foi realizado o rebaixamento da calha do rio, para escoramento dos dutos anteriormente instalados sem qualquer proteção que impedisse a ocorrência da erosão de escavação do fundo e sem qualquer proteção para a margem do rio. Os dutos foram implantados transversalmente ao leito do rio (Figura 3a). Ao mesmo tempo do retaludamento do trecho de margem degradada (Figura 3b), foi promovida a elevação do nível da base, sendo a calha e os dutos protegidos com colchão Reno® (Figura 3c e 3d), impedindo a sua exposição, que contribuía para alteração do fluxo normal da água na calha do rio em direção às margens. Ocorreu também a implantação do geotêxtil, tanto no talude quanto na planície de inundação, e o posterior plantio de espécies leguminosas. O fluxo de água na calha foi restabelecido a partir da nova condição possibilitada por essa geotécnica.

A utilização de geotêxtil no talude da margem em parte da planície de inundação, associada com espécies vegetais leguminosas, criou um microambiente que auxiliou outras espécies a se estabelecerem, possibilitando a proteção do talude mediante a sucessão ecológica. Na base do talude foi implantado colchão Reno®, estendendo-se até metade da altura do talude, assim como na sua calha. A metade superior do talude foi recoberta com geotêxtil. A introdução de elementos artificiais para a recuperação das margens do rio alterou a paisagem, no entanto essa alteração não deve ser considerada negativa, uma vez que a paisagem degradada foi substituída, com o auxílio da bioengenharia de solos, por outra menos 
agressiva do ponto de vista estético. A presença desses elementos contribuiu para que o equilíbrio inicial modificado fosse, aos poucos, sendo restabelecido.

\section{A revegetação da margem do rio}

A vegetação do rio Paramopama foi o primeiro elemento avaliado que apresentou mudanças. A urbanização pouco interfere na área de estudo, apresentando somente algumas habitações localizadas no seu entorno, não sendo explorada para mineração, como extração de areia. Com relação à agropecuária, o trecho avaliado constantemente é usado como área de pastagem e bebedouro para o rebanho bovino.

Durante o monitoramento, foi observado que a bioengenharia de solos vem possibilitando a recuperação ambiental do trecho degradado do rio, por meio da recuperação da biodiversidade local. A polinização tem se constituído em fator que promoveu o povoamento da área com espécies endêmicas. Para o perfeito funcionamento desse processo, as plantas desenvolvem atrativos nas flores para atrair os agentes dispersores. Insetos, pássaros e morcegos, ao se alimentarem e visitarem diversas flores, executam o processo de polinização (MACEDO et al., 1993). Além da zoocoria, na área estudada a dispersão de sementes parece vir ocorrendo por meio da anemocoria, em que o agente dispersor é o vento, e também por hidrocoria, em que as sementes são dispersadas pela ação da água.

As suas margens vêm sendo povoadas por espécies não só pertencentes àquelas plantadas, mas também por outras espécies identificadas, tais como Mimosa pudica L. (dormideira), Stylosanthes guianensis Aubl. (estilosante), Raphunus sativus L. (nabo-forrageiro), Cyperus flavus J. Presl e C. Presl (barba-de-bode), Cratylia mollis Mart. Ex. Benth. (camaratuba) e Capsicum baccatum (pimenta-dedo-demoça), registradas no levantamento florístico realizado. Também vem sendo observada a ocorrência de animais pertencentes às classes Insecta, Reptilia e Aves, que parecem vir auxiliando no processo de dispersão de sementes. O fluxo não mais é impedido pela presença de bancos de areia, antes depositadas ao longo da calha do rio.

No período compreendido entre setembro/2006 e maio/2008, observou-se que as espécies plantadas (crotalária, calopogônio, feijão-guandu e vetiver) recobriram as margens direita e esquerda, criando condições de estabilização do talude, povoando a planície de inundação e contribuindo para o controle da erosão.

\section{Evolução da alteração da paisagem}

A alteração da paisagem pode ser identificada a partir de estágios que se sucedem no período de janeiro de 2005 a maio de 2008. Observa-se a expressão da degradação representada pelo assoreamento da margem, levando à formação de pequenos bancos de areia na calha do rio. A vegetação ciliar nativa se mostra quase ausente, percebendo-se somente a ocorrência de gramíneas invasoras provenientes da área de pastagem próxima, ou mesmo de espécies herbáceas oportunistas.

A intervenção humana modificou a paisagem com a introdução de elementos de bioengenharia, como colchão Reno® e geotêxteis, que alteram a paisagem degradada (Figura 4a). O retaludamento redesenhou a inclinação das margens antes verticalizadas, e a implantação do colchão Reno® também contribuiu para modificar a paisagem degradada desse trecho do rio. A implantação dos geotêxteis, associada com o plantio das leguminosas, proporcionou o desenvolvimento de uma cobertura vegetal densa, protegendo tanto o talude quanto a planície de inundação da ação do processo erosivo, criando também um ambiente favorável, pela conservação da umidade, à ocorrência de outras espécies no processo de dispersão (Figura 4b). As espécies classificadas como pioneiras possibilitaram a recuperação do solo, permitindo o estabelecimento das espécies plantadas, assim como as endêmicas, que aos poucos voltaram a compor a paisagem.

Nas figuras $4 \mathrm{c}$ e $4 \mathrm{~d}$, a vegetação plantada se apresenta completamente estabelecida, com margens povoadas por uma cobertura vegetal outrora ausente. A presença da vegetação tem permitido o retorno gradual da fauna local, contribuindo para os processos de dispersão de sementes. O processo erosivo, antes acelerado, vem sendo controlado, assim como o assoreamento do rio. A paisagem em processo de recuperação sinaliza que, com o passar do tempo, as espécies plantadas, todas arbustivas ou herbáceas, serão substituídas, naturalmente, pelas espécies endêmicas, que expressarão a sua melhor competitividade em um ambiente mais favorável ao seu desenvolvimento.

De acordo com a classificação sugerida por Lima et al. (2004), a área antes das ações de recuperação era considerada como de altíssimo grau de antropização, devido à forte influência antrópica. 
Com a intervenção antrópica através da bioengenharia de solos, a paisagem resultante do uso dessa técnica foi classificada como de alto grau de antropização, uma vez que foi observada a presença de vegetação secundária. No entanto, essa interferência foi necessária para a recuperação das margens.

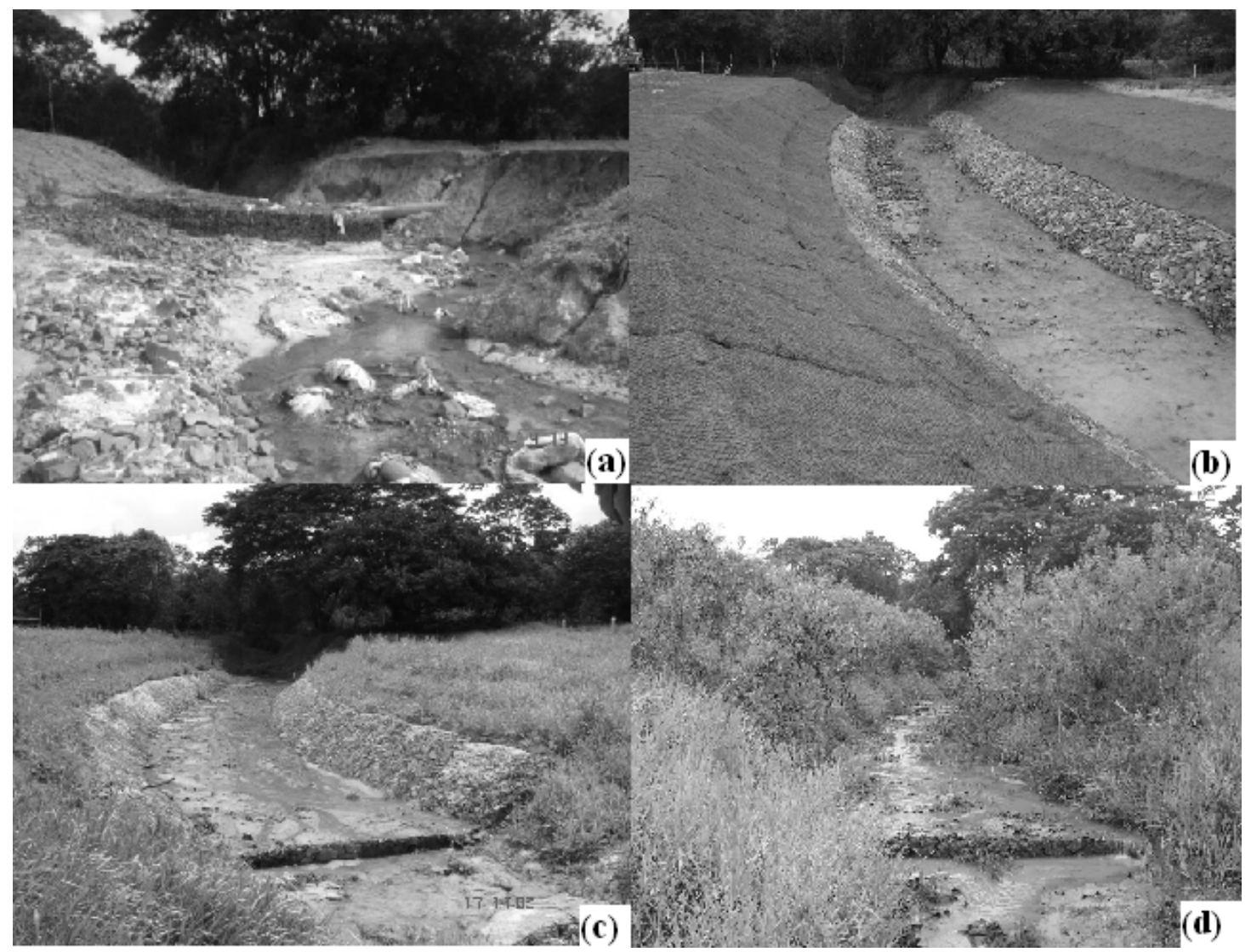

Figura 4. Evolução da alteração da paisagem no rio Paramopama.

Figure 4. Evolution of landscape changes at Paramopama river.

\section{CONCLUSÕES}

- A técnica de bioengenharia de solos mostrou-se eficiente no que se refere à recuperação da paisagem, além de propiciar condições ecológicas para a recuperação do ecossistema ribeirinho.

- O uso do geotêxtil, possibilitando o surgimento de condições ideais para o desenvolvimento da vegetação, mostrou-se eficiente para o controle da erosão e no que se refere à recomposição da paisagem.

- As alterações ocorridas na paisagem estão relacionadas ao grau de recobrimento do solo propiciado pelo desenvolvimento gradual da vegetação.

- A técnica de bioengenharia de solos empregada auxiliou no desenvolvimento das espécies semeadas/plantadas, no estabelecimento de indivíduos de outras espécies, além de ter sido fator determinante para a evolução do grau de antropização de altíssimo para alto.

\section{REFERÊNCIAS}

BERTRAND, G. Paisagem e geografia física global: esboço metodológico. Cadernos de Ciências da Terra. São Paulo: Instituto de Geografia da USP. n. 13. p. 1 - 27, 1972. 
CARRIJO, B. R.; BACARRO, C. A. D. Análise sobre a erosão hídrica na área urbana de Uberlândia (MG). Caminhos de Geografia, v. 1, n. 2. p. 70 - 83. 2000.

DAVIDE, A. C.; PINTO, L. V. A.; MONNERAT, P. F.; BOTELHO, S. A. Nascente: o verdadeiro tesouro da propriedade rural. Lavras: Editora UFLA, 2002. $19 \mathrm{p}$.

DEFESA FLORESTAL LTDA (DEFLOR). Catálogo de produtos e serviços de bioengenharia. Belo Horizonte, 2005. $26 \mathrm{p}$.

EMPRESA BRASILEIRA DE PESQUISA AGROPECUÁRIA (EMBRAPA). Sistema brasileiro de classificação de solos. Brasília: EMBRAPA Produção de Informação; Rio de Janeiro: EMBRAPA Solos, 1999.

FERREIRA, D. A. C.; DIAS, H. C. T. Situação atual da mata ciliar do ribeirão São Bartolomeu em Viçosa, MG. Revista Árvore, Viçosa, v. 2, n. 4, p. 617 - 623. 2004.

GOMES, L. G. N. A bioengenharia como ferramenta para restauração ambiental das margens do rio São Francisco. São Cristóvão, SE. Dissertação (Mestrado em Desenvolvimento Regional) Universidade Federal de Sergipe, São Cristóvão, 2005.

GRAY, D. H.; SOTIR, R. B. Biotechnical and soil bioengineering slope stabilization: a pratical guide for erosion control. New York: Wiley, 1996. 377 p.

GREGORY, S. V.; SWANSON, F. J.; McKEE, W. A.; CUMMINS, K. W. An ecosystem perspective of riparian zones. BioScience, Washingon, v. 41, n. 8, p. 540 - 551, 1992.

HOWE, H. F.; SMALLWOOD, J. Ecology of seed dispersal. Annual Review Ecology Systems, v. 13, p. $201-228,1982$.

HOLANDA, F. S. R.; ROCHA, I. P. da; OLIVEIRA, V. S. de. Estabilização de taludes marginais com técnicas de bioengenharia de solos no Baixo São Francisco. Revista Brasileira de Engenharia Agrícola e Ambiental, Campina Grande, v. 12, n. 6, 2008, p. 570 - 575.

LANDOVSKY, G. S.; BATISTA, D. B.; ARAKI, H. Análise da qualidade visual da paisagem da região de Tibagi, PR, aplicando o sensoriamento remoto. Revista Brasileira Engenharia Agrícola e Ambiental. v. 10, n. 1, p. 188 - 195, 2006.

LIMA, E. de C. de.; SANQUETTA, C. R.; KIRCHNER, F. F.; FERRETTI, E. R. Qualidade da paisagem: estudo de caso na floresta ombrófila mista. Floresta, v. 34, n. 1, p. 45 - 56, 2004.

LUCAS, O. W. R. The design of forest landscapes. New York: Oxford University Press. 1991. 391 p.

MACCAFERRI. Colchão Reno®. Disponível em <http://www.maccaferri.com.br>. Acesso em 09/10/2008.

MACEDO, A. C. de; KAGEYAMA, P. Y.; COSTA, L. G. S. Revegetação: matas ciliares e de proteção ambiental. Fundação Florestal, 1993.

MACIEL FILHO, C. L. Introdução à geologia de engenharia. 2. ed. Santa Maria, Editora da UFSM, 1997.

MARTÍNEZ-RAMOS, M.; SOTO-CASTRO, A. Seed rain and advanced regeneration in a tropical rain forest. Vegetation, v. 107/108. p. 299 - 318, 1993.

PARROTA, J. A.; KNOWLES, O. H.; WUNDERLE, J. M. Development of floristic diversity in 10-yearold restoration forests on a bauxite mined site in Amazonia. For. Ecol. Manage, v. 99, p. 21 - 42, 1997.

SANTOS, E. M. de O. Degradação ambiental na bacia do rio Paramopama no município de São Cristóvão em Sergipe (Brasil). Monografia (Especialização em Geologia Sedimentar e Hidroambiental) - Universidade Federal de Sergipe, São Cristóvão, 2007.

SCHIELTZ, H. M.; STERNE, R. Ground bioengineering techniques for slope protection and erosion control. Blackwell Science, 1996. 186 p. 
VIANA, V. M. Conservação da biodiversidade de fragmentos de florestas tropicais em paisagens intensamente cultivadas. In: FONSECA, G. A. B. de; SCHMINK, M.; PINTO, L. P.; BRITO, F. (Eds.)IAbordagens interdisciplinares para a conservação da biodiversidade e dinâmica do uso da terra no novo mundo. Gainesville: Conservation International do Brasil/Universidade Federal de Minas Gerais/University of Florida, Belo Horizonte: UFMG: Conservation International, 1995. p. 135 - 154.

WHITTAKER, R. J.; JONES, S. H. The role of frugivorous bats and birds in the rebuilding of a tropical forest ecosystem, Krakatau, Indonesia. Journal Biogeography, v. 21. p. 245 - 258. 1994.

WUNDERLE, J. M. The role of animal seed dispersal in accelerating native forest regeneration on degraded tropical lands. For. Ecol. Manage, 99. 1997. p. 223 - 235. 